\title{
A multi-response optimization of the multi-directional forging process for aluminium 7075 alloy using grey-based taguchi method
}

\author{
C. Obara' ${ }^{1}$ - F. M. Mwema ${ }^{1}$ J. N. Keraita ${ }^{1}$ - H. Shagwira ${ }^{1}$ 'J. O. Obiko ${ }^{2}$
}

Received: 12 November 2020 / Accepted: 19 March 2021

Published online: 01 May 2021

(c) The Author(s) 2021 OPEN

\begin{abstract}
The multi-directional forging process of aluminium alloy 7075 (AA 7075) is studied using Deform 3D Version 11.0 simulation software. This process results in grain refinement in the bulk material. The 7075 aluminium alloy is used widely in the aerospace and automobile industries. Thermomechanical processing affects the mechanical properties of this alloy. This study focuses on optimising process parameters that affect the multi-directional forging using simulation. In the Taguchi design of experiment, four-factors and five levels are selected. The process input parameters considered are temperature, the strain per pass, the plunger speed, and the friction coefficient $(\mu)$. From Taguchi's orthogonal array, forging simulations are undertaken and analysed. The significance of the process output parameters: material damage, stress and strain are analysed by analysis of variance. The results show that the friction coefficient and strain per pass highly affect the stress/strain distribution. Grey relational analysis is adopted to determine the optimum process parameters. The results show that the optimal combination of parameters is: temperature $\left(200^{\circ} \mathrm{C}\right)$, plunger speed $(5 \mathrm{~mm} / \mathrm{s})$, friction coefficient (0.6), and strain per pass (0.6). Confirmation of simulation is carried out using the optimum input parameters. From the simulation results, the grey relational grade's optimal parameters have the highest maximum effective strain of 5.57, maximum effective stress of $665 \mathrm{MPa}$, and maximum damage of 0.416 compared to other simulated results.
\end{abstract}

Keywords Multi-directional forging · Grey relational analysis · Taguchi · Damage · Effective stress · Effective strain

\section{Introduction}

Multi-directional forging (MDF) is an important severe plastic deformation (SPD) process used in the grains refinement of metals and their alloys [1]. The process is cheap and easy to carry out because it does not need complex equipment when compared to other SPD processes, such as high-pressure torsion (HPT) and accumulative roll bonding (ARB) [2]. Additionally, it is capable of forging large samples. In the MDF process, materials are subjected to very high strains without necessarily resulting in dimensional changes to the samples. The samples are compressed in all the faces, one face after another repeatedly, as shown in Fig. 1. The compression results in a decrease in grain sizes and improved mechanical properties [3]. Noda et al. reported that superplastic behaviour also improved due to accumulated redundant plastic deformation [4].

The MDF is a nonlinear process that can result in undesirable results due to variations in various factors before or during processing. Some of these factors include; the geometry and size of the specimen, temperature changes, plunger speed, number of passes, coefficient of friction, strain per pass, forging equipment errors, strain rate, positional errors and material properties [5-7]. Combining any of these uncertainties could result in production losses, product distortion (geometry or/and quality), equipment

C. Obara, obaradaddie@gmail.com | 'Department of Mechanical Engineering, Dedan Kimathi University of Technology, Nyeri 10143, Kenya. ${ }^{2} \mathrm{School}$ of Chemical and Metallurgical Engineering, University of the Witwatersrand, Johannesburg, South Africa.

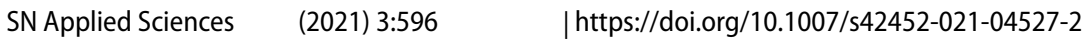




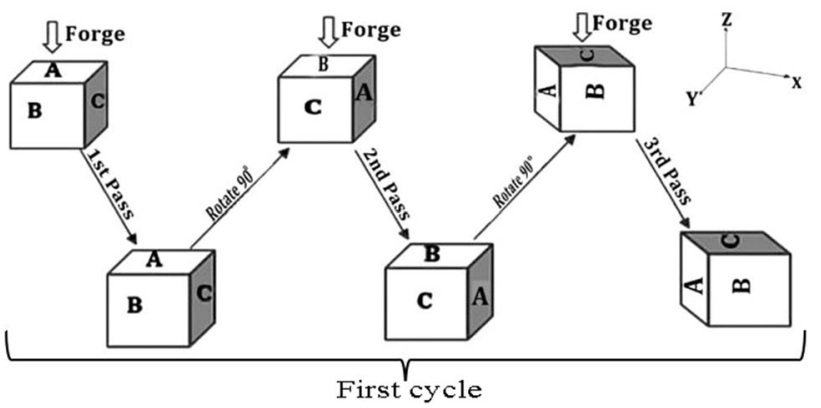

Fig. 1 A general schematic diagram of the MDF process

failure and sometimes accidents. Therefore, identification, control and optimisation of these parameters minimizes the production losses and improves the production process.

During the MDF process, various studies have used input parameters differently. Some researches have been conducted at temperatures ranging from room temperature [8] to extremely high temperatures of up to $500 \mathrm{~K}$ [9, 10]. Other input process parameters studied include; strain per pass (the strain of every single pass ranging from 0.2 to 0.7$)$, die velocity, friction coefficient, and the geometry of the sample (size and shape) [9]. Most researchers have considered some variables of the process as constants while varying others to examine how they affect the MDF $[3,8,11-13]$. Although studies on the MDF process have been widely conducted, the literature on process optimisation is scanty.

To carry out the optimisation reliably and at less costly means, the use of Deform ${ }^{\mathrm{TM}} 3 \mathrm{D}$, a software with Finite Element Method (FEM) is preferred [14]. Deform ${ }^{\text {TM }} 3 D$ has a well-written algorithm that can mimic the real process effectively [15]. Other simulation softwares available for metal forming operations include; Transvalor Forge ${ }^{\mathrm{TM}}$, ANSYS, Simufact.forming ${ }^{\mathrm{TM}}$, Hyperextrude, SUPERFORM, ABACUS and MSC.MARC ${ }^{\mathrm{TM}}$ [16-18]. To get optimised output parameters for the process, several simulations are required. Therefore, the Taguchi optimisation methods crucial in reducing the number of simulations through the design of experiments (DOE) [19]. However, when several output responses are viewed with interdependent goals, the method is unsuitable. Therefore, the Grey-based Taguchi approach was developed in 1982, by Deng Ju-long to determine solutions to multi-response optimisation data [20]. The grey relational analysis helps solve complex interrelationships for multiple responses based on the theory of the grey system $[21,22]$. After evaluating each response, a grey relational grade is obtained. The multiple responses for optimisation are then transformed into a single optimization grade. The optimum conditions are determined from the grade rank.

In this study, the grey-based Taguchi approach quality tool was applied to optimise the process parameters of the multi-directional forging simulations of AA 7075. The main focus was to minimize damage, maximize effective strain and effective stress. This paper is organised as follows; section one is an introduction, where the general MDF process optimisation details of AA 7075 are discussed. The simulation and optimisation methodologies are outlined and discussed in section two. Section three provides results obtained after simulation and are later discussed in section four. Section five concludes the paper's main findings, research contributions and recommends future potential studies.

\section{Methodology}

In this study, MDF simulation was carried out using a finite element software called Deform ${ }^{\mathrm{TM}} 3 \mathrm{D}$ (version 11.0). The optimisation of the process parameters during the MDF simulation was carried out using Taguchi's design of experiments. The obtained results were analyzed using $\mathrm{S} / \mathrm{N}$ ratios, ANOVA and grey relational analysis to determine optimum parameters.

\subsection{Design of experiment}

The design of experiments by the Taguchi technique is a powerful instrument for analyzing and modelling the influence of input parameters on the output quality. During the analysis, the most significant stage in the design of experiments is the choice and control of the input variables. The Taguchi method helps to efficiently determine the range of input data in the design stage, reducing the cost and time [23]. In the current study, four factors were considered, each having five levels to represent the various factors' data range. The four factors were; temperature, coefficient of friction, strain per pass and plunger speed. These factors were chosen because they have been shown in the literature to be the most significant in forging operations [10]. The respective levels of the factors were chosen based on the published experimental results and the Taguchi designs [2, 24]. Table 1 gives the identified process parameters and levels. The interaction of the four process parameters at the five levels was designed using 
a full factorial $\mathrm{L}_{25},\left(5^{4}\right)$ orthogonal array and the results are shown in Table 2.

\subsection{Simulation model}

In this study, workpieces of AA 7075, having dimensions of $50 \mathrm{~mm} \times 50 \mathrm{~mm} \times 50 \mathrm{~mm}$, were used. The material properties of the workpiece are available in the commercial Deform $^{\text {TM }} 3 \mathrm{D}$ software database. Figure 2 shows the simulation set-up with (a) a schematic diagram of the dies and the meshed workpiece and (b) the simulation in progress at step 30. As shown, the MDF simulation set-up consists of a top and bottom die, which are assumed to be rigid, while the workpiece is assumed to be plastic. The bottom die is fixed while the top die moves in a normal direction to the workpiece. Using the primitive modeller of the Deform ${ }^{\text {TM }}$ $3 \mathrm{D}$ tool, the geometry and dimensions of the rectangular dies and workpiece were developed. The die dimensions were $200 \mathrm{~mm} \times 200 \mathrm{~mm} \times 30 \mathrm{~mm}$. The simulation process was conducted at a room temperature of $25^{\circ} \mathrm{C}$ in an isothermal mode. The convectional coefficient was taken as $0.02 \mathrm{~N} /\left(\mathrm{s} \mathrm{mm}{ }^{\circ} \mathrm{C}\right)$, whereas the coefficient of heat transfer used during the simulation; between the dies and the workpiece was taken as $5 \mathrm{~W} /\left(\mathrm{m}^{2} \mathrm{~K}\right)(\mathrm{g})$. The simulation type used was Lagrangian incremental with a direct iterative method [25]. The global re-meshing and conjugate-gradient solver were selected. The workpiece was discretised into 20,000 tetrahedral elements. Sensitivity analysis was used to determine the optimum number of elements. The use of tetrahedral elements is preferred as it gives a better and fitting mesh algorithm with only minor distortions. This type of mesh results in more accurate data within a short computation time, compared to the cartesian mesh type, even when the number of elements is high in the simulation model [26].

\subsection{Optimisation using the grey Taguchi method}

The Taguchi method is vital in developing the optimum parameters. The signal-to-noise ratio $(\mathrm{S} / \mathrm{N})$ is instrumental

Table 1 MDF input parameters and their respective levels

\begin{tabular}{|c|c|c|c|c|}
\hline \multirow{2}{*}{$\begin{array}{l}\text { Levels of the } \\
\text { MDF param- } \\
\text { eters }\end{array}$} & \multicolumn{4}{|c|}{ MDF parameters } \\
\hline & $\begin{array}{l}\text { Tempera- } \\
\text { ture }\left({ }^{\circ} \mathrm{C}\right)\end{array}$ & $\begin{array}{l}\text { Plunger } \\
\text { speed } \\
\left(\mathrm{mm} \mathrm{s}^{-1}\right)\end{array}$ & $\begin{array}{l}\text { Friction } \\
\text { coefficient } \\
(\mu)\end{array}$ & $\begin{array}{l}\text { Strains } \\
\text { per pass }\end{array}$ \\
\hline 1 & 25 & 5 & 0.2 & 0.2 \\
\hline 2 & 100 & 10 & 0.3 & 0.3 \\
\hline 3 & 200 & 15 & 0.4 & 0.4 \\
\hline 4 & 300 & 20 & 0.5 & 0.5 \\
\hline 5 & 400 & 25 & 0.6 & 0.6 \\
\hline
\end{tabular}

Table 2 L25 orthogonal array of Taguchi method of factors combination

\begin{tabular}{|c|c|c|c|c|}
\hline \multirow[t]{2}{*}{ Simulation no } & \multicolumn{4}{|c|}{ MDF input parameters } \\
\hline & $\begin{array}{l}\text { Tem- } \\
\text { perature } \\
\left({ }^{\circ} \mathrm{C}\right)\end{array}$ & $\begin{array}{l}\text { Plunger } \\
\text { speed } \\
\left(\mathrm{mm} \mathrm{s}^{-1}\right)\end{array}$ & $\begin{array}{l}\text { Friction } \\
\text { coefficient } \\
(\mu)\end{array}$ & Strain per pass \\
\hline 1 & 25 & 5 & 0.2 & 0.2 \\
\hline 2 & 25 & 10 & 0.3 & 0.3 \\
\hline 3 & 25 & 15 & 0.4 & 0.4 \\
\hline 4 & 25 & 20 & 0.5 & 0.5 \\
\hline 5 & 25 & 25 & 0.6 & 0.6 \\
\hline 6 & 100 & 5 & 0.3 & 0.4 \\
\hline 7 & 100 & 10 & 0.4 & 0.5 \\
\hline 8 & 100 & 15 & 0.5 & 0.6 \\
\hline 9 & 100 & 20 & 0.6 & 0.2 \\
\hline 10 & 100 & 25 & 0.2 & 0.3 \\
\hline 11 & 200 & 5 & 0.4 & 0.6 \\
\hline 12 & 200 & 10 & 0.5 & 0.2 \\
\hline 13 & 200 & 15 & 0.6 & 0.3 \\
\hline 14 & 200 & 20 & 0.2 & 0.4 \\
\hline 15 & 200 & 25 & 0.3 & 0.5 \\
\hline 16 & 300 & 5 & 0.5 & 0.3 \\
\hline 17 & 300 & 10 & 0.6 & 0.4 \\
\hline 18 & 300 & 15 & 0.2 & 0.5 \\
\hline 19 & 300 & 20 & 0.3 & 0.6 \\
\hline 20 & 300 & 25 & 0.4 & 0.2 \\
\hline 21 & 400 & 5 & 0.6 & 0.5 \\
\hline 22 & 400 & 10 & 0.2 & 0.6 \\
\hline 23 & 400 & 15 & 0.3 & 0.2 \\
\hline 24 & 400 & 20 & 0.4 & 0.3 \\
\hline 25 & 400 & 25 & 0.5 & 0.4 \\
\hline
\end{tabular}

in obtaining the means of the output responses. Depending on the desired quality, the following characteristics of the $\mathrm{S} / \mathrm{N}$ ratios were applied in this study; (i) the lower-thebetter represented by Eq. 1 to minimize damage and (ii) the higher-the-better, represented by Eq. 2 to maximise effective stress and strain. The greater the value of the $S / N$, the better the attainable quality.

Lower - the - better $S / N(\eta)=-10 \log _{10}\left(\frac{1}{n} \sum_{i=1}^{n} y_{i j}^{2}\right)$

Higher - the - better $S / N(\eta)-10 \log _{10}\left(\frac{1}{n}\right)\left\{\sum_{i=1}^{n} \frac{1}{y_{i j}^{2}}\right\}$

where $n$ is number of experiments and $y_{i j}=$ output response value where $i=1,2, \ldots \ldots \ldots, n ; j=1,2 \ldots k$. 

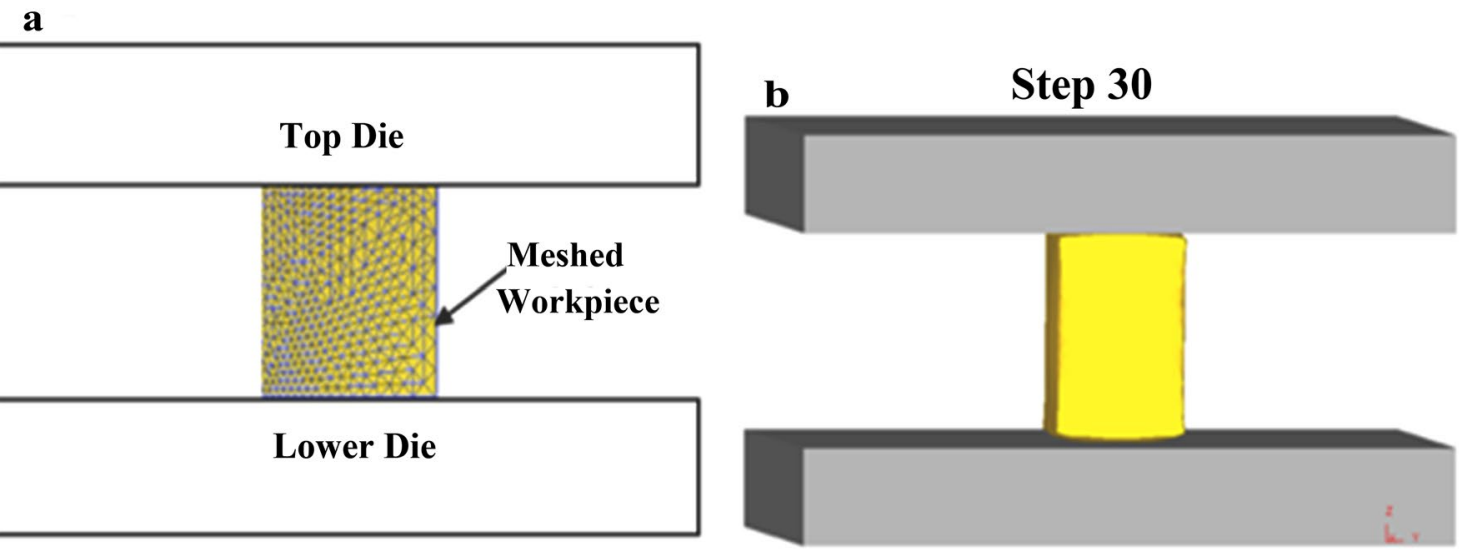

Fig. 2 A schematic diagram of a meshed workpiece (a) and a picture of simulation progress (b)

\subsubsection{Using the grey relational analysis (GRA) to determine the optimum process parameters}

The grey relational analysis (GRA) is used for multi-objective optimisation, and in this study, there were three objectives; (i) to minimize damage, (ii) to maximise effective stress and (iii) to maximise effective strain. The GRG combines different interrelated performance objectives to form a single value called grade. The grade is then used to optimise multi-response problems. The general flow of the process is summarised in Fig. 3.

Before computing the grey correlational coefficients, the grey data analysis must be carried out. The $\mathrm{S} / \mathrm{N}$ ratios are useful for normalization of the results between the range 0 and 1 using Eqs. 3 and 4. Normalizing helps reduce the variability of the results and lowers the impact of the adoption of different units.
The grey relation coefficient attempts to show the affiliation between ideal results and the actual normalized results. To compute the grey relational coefficient for the normalized ratios, the expression in Eq. 6 is applied,

$G C_{i j}=\frac{\Delta \min +\lambda \Delta \max }{\Delta_{i j}+\lambda \Delta \max }$

where $Z_{\mathrm{ij}}$ is the next arrangement after the processed data, $j=1,2, \ldots, n ; i=1,2, \ldots, n, n$ is the nth number of the data results from the experiment and $\mathrm{GC}_{\mathrm{ij}}$ is the grey relational coefficient for experiment number $i$ and the dependent response number $\mathrm{j}$.

The grey relational grade is set after computing the mean value of the grey relational coefficient for each performance characteristic. The total performance characteristic for multi-response processes depends on the determined grey relational grade. To calculate the overall grey

For the smaller the better, $Z i j=\frac{\operatorname{Max}\left(y_{i j}, \quad i=1,2, \ldots, n\right)-y_{i j}}{\operatorname{Max}\left(y_{i j}, \quad i=1,2, \ldots, n\right)-\operatorname{Min}\left(y_{i j}, \quad i=1,2, \ldots, n\right)}$

For the larger the better,$Z i j=\frac{y_{i j}-\operatorname{Min}\left(y_{i j}, \quad i=1,2, \ldots, n\right)}{\operatorname{Max}\left(y_{i j}, \quad i=1,2, \ldots, n\right)-\operatorname{Min}\left(y_{i j}, \quad i=1,2, \ldots, n\right)}$

Normalization is then carried out after getting $\Delta$ (absolute difference) from the $y_{o i}$ and $y_{i j}$ values which can be said to be a loss or a deviation from the target and it can be expressed as;

$\Delta=Z_{o j}-Z_{i j}=1-Z_{i j}$

where $Z_{o j}$ is the optimum or ideal value that has been normalized for the jth response and it is equal to $1, Z_{i j}$ is the value of the jth response after normalization. $\lambda$ is considered as a distinct coefficient that ranges from 0 to 1 . relational grade $\left(\mathrm{G}_{\mathrm{i}}\right)$ for ith experiment and $\mathrm{m}$ number of the responses, Eq. 7 is used.

$G_{i}=\frac{1}{m} \sum G C_{i j}$

The Principal Component Analysis (PCA) was used in this work to approximate the weight. 


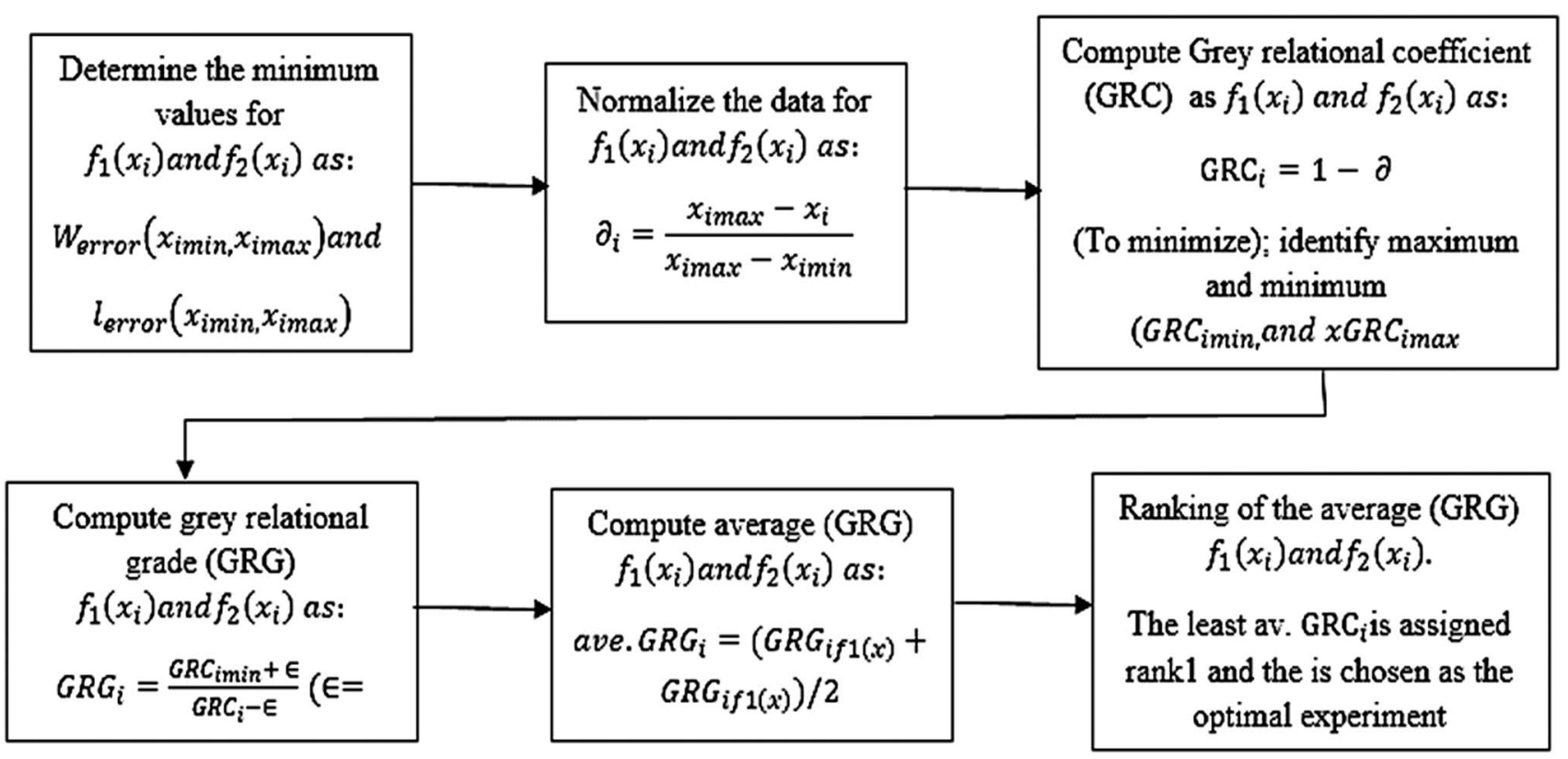

Fig. 3 Summary of the grey relational analysis model

\subsubsection{Principal component analysis (PCA)}

Various studies have used PCA to determine the weight (correlation) of different performance characteristics in various processes. Some of these studies include; Dubey \& Yadava, who studied how to improve the cutting outcome of Nd:YAG pulsed laser beam cutting (LBC), the results obtained were found to be similar to experimental results [27]. Viswanathan et al. used Taguchi, grey relational analysis and PCA to optimise turning parameters of magnesium alloy. These methods proved to be effective for multi-response optimisation [28].

The procedure of the PCA involves [29].

The output quality performance characteristics are identified then normalization is carried out using Eqs. 8 and 9.

For minimization, $x_{i}^{*}=\frac{\min x_{i}(k)}{x_{i}(k)}$

For maximization, $x_{i}^{*}=\frac{x_{i}(k)}{\max _{i}(k)}$

where $x_{i}^{*}, \mathrm{k}$ is the standardized ith experiment and kth is the output data. In this study, the damage was minimized and maximization of effective stress and strain was done. Standardization was carried out to transform the variables into the same scale.

The covariance matrix is then computed using Eq. 10 to determine whether the variables at the input relate to each other; by determining the variation from the mean for each of them.

Cov.matrix $(M)=\left|\begin{array}{cccc}M_{1,1} & M_{1,2} & \cdots & M_{1, n} \\ M_{2,1} & M_{2,3} & \cdots & M_{2, n} \\ \vdots & \vdots & \cdots & \vdots \\ M_{m, 1} & M_{m, 2} & \cdots & M_{m, n}\end{array}\right|$

where

$M_{i j}=\frac{\operatorname{cov} y_{i}^{*}(j), y_{i}^{*}(k)}{\sigma y_{i}^{*}(j) \times y_{i}^{*}(k)}$

Cov. means covariance and $\sigma$ the standard deviation, $i=1$, $2,3 \ldots \mathrm{m}$, and $\mathrm{m}$ is the number of experiments, $\mathrm{k}=1,2,3$ .... $n, n$ is the number of outputs measured.

Computation of eigenvalues and eigenvectors are then determined using Eq. 12. The eigenvectors computed are ordered according to their eigenvalues in descending order, to aid in determining the principal components significance order.

$\left(M-\lambda_{k} i M\right) V_{i k}=0$

where eigenvalues of $\lambda_{k}=\sum_{k=1}^{n} \lambda_{k}=n, \mathrm{k}=1,2,3 \ldots \mathrm{n}$., eigenvectors of the corresponding eigenvalues are given by $v_{i k}=\left[a_{k 1}, a_{k 2}, \ldots . a_{k n}\right]$.

Finally, through the eigenvector, the weight factor of each output response of the principal component is calculated using Eq. 13. 
$Y_{m k}=\sum_{i=1}^{n} y_{i}^{*}(k) * V_{i k}$

\subsubsection{Determining the optimum parameters and their level}

This Grey relational grade method was used to transform the output responses of the multi-objective optimisation problem into a single optimised solution. The higher the grey relation grade, the closer the outcome to the ideal normalized value and the higher the grade value, the closer the factors in the combination are optimum.

\subsubsection{Analysis of variance}

The primary objective of the analysis of variance (ANOVA) is to use a statistical system to identify the influence of each factor. The Taguchi scientific design is unable to determine the impact of input variables over the entire process, but when using ANOVA by the percentage contribution, the effects can be determined. The cumulative total of the squared deviations is broken down into two: the cumulative of the squared absolute deviation due to the sum of squared error and each parameter. Each percentage in the total sum of the squared deviations is applied to evaluate the significance of the changes in the performance characteristics in the method parameter. Usually, when the F(variance ratio) value is significant, changes in the process parameters significantly impact performance. The degrees of freedom of an effect should be taken into account, i.e., a mean square effect of the factor will help decide if the effect is weak-the greater the mean square, the stronger the effect.

\section{Results}

The simulations were carried out as per the Taguchi design of experiment and corresponding values of the responses were recorded in Table 3. The output responses include; maximum damage, maximum effective strain and stress.

Damage is a characteristic that leads to the cracking or fracture of a material. The extent of the crack is dependent on the induced stresses in the material. The cracks created during deformation enhance fracture when the material is in use [30]. Effective stress is directly related to plastic deformation and higher effective stress is desirable during deformation. A reduction in effective stress results in low material strength. The quantity of effective strain is critical in measuring the degree of deformation within a material [31]. Higher values of effective strain are preferred.
The $\mathrm{S} / \mathrm{N}$ ratios for the output responses in Table 4 were computed using the Taguchi criteria, represented in Eqs. 1 and 2. Normalization of the $\mathrm{S} / \mathrm{N}$ values was then computed using Eq. 3 for damage and Eq. 4 maximum effective stress and strain. The absolute difference was computed by deducting each of the normalized values of the $\mathrm{S} / \mathrm{N}$ ratio from the maximum normalized value according to Eq. 5 . Table 4 shows the results of $\mathrm{S} / \mathrm{N}$ ratios, normalization and absolute difference.

The grey relational coefficient values of the normalized ratios were determined as per Eq. 6 . The distinguishing coefficient values were substituted in Eq. 7. Usually, when the outputs have an equal weightage, 0.5 is used [32]. Most researchers widely assumed $\xi=0.5$. However, some studies question this practice. Mahmoudi et al. showed that a variation $\xi$ influenced the ranking contrary to the other studies [33]. The distinguishing coefficient ranges $\zeta \in[0,1]$. The maximum value equals one and the minimum equals zero $[34,35]$.

In this study, the PCA was used to determine the distinguishing coefficient. The PCA was analysed in Minitab software, and the results are shown in Fig. 4 and Table 5. According to the PCA results, the damage was found to have more weight, in this study it was assigned as 0.6 , followed by effective strain, 0.3 and finally effective stress, 0.1 .

From the values of the grey relational coefficient, the grey relational grade was determined according to Eq. 7 . The results are shown in Table 6.

\subsection{Signal to noise ratio analysis}

Main effect plots for $\mathrm{S} / \mathrm{N}$ are useful in determining the optimal parameters. Figure 5 shows the main effects plot of $\mathrm{S} / \mathrm{N}$ ratios for maximum damage, maximum effective strain, maximum effective stress and grey relational grade. It was observed that when using the smaller is better quality characteristic for the damage, the factors are optimum at the following conditions; temperature $-400^{\circ} \mathrm{C}$, plunger speed $-10 \mathrm{~mm} / \mathrm{s}$, friction coefficient -0.6 and strain per pass-0.6. The optimum values for all other responses are as recorded in Table 7. The temperature showed a decreasing increasing trend, implying that its influence on the outputs was not linear. A change in strain per pass would affect the output differently depending on the strains.

\subsection{Analysis of variances}

The analysis of variance was carried out as shown in Table 8 to determine the significance levels and the contribution of the factors. Additionally, the error contribution 
Table 3 Table of Taguchi response-output L25 orthogonal array

\begin{tabular}{|c|c|c|c|c|c|c|c|}
\hline \multirow[t]{2}{*}{ S/no } & \multicolumn{4}{|c|}{ MDF Input parameters } & \multicolumn{3}{|c|}{ Output responses } \\
\hline & $\begin{array}{l}\text { Tempera- } \\
\text { ture }\left({ }^{\circ} \mathrm{C}\right)\end{array}$ & $\begin{array}{l}\text { Plunger } \\
\text { speed } \\
\left(\mathrm{mm} \mathrm{s}^{-1}\right)\end{array}$ & $\begin{array}{l}\text { Friction } \\
\text { coefficient } \\
(\mu)\end{array}$ & $\begin{array}{l}\text { Strains } \\
\text { per pass }\end{array}$ & Max. damage & $\begin{array}{l}\text { Max. Strain- } \\
\text { effective }\end{array}$ & $\begin{array}{l}\text { Max stress- } \\
\text { effective } \\
(\mathrm{MPa})\end{array}$ \\
\hline 1 & 25 & 5 & 0.2 & 0.2 & 0.111 & 0.956 & 640 \\
\hline 2 & 25 & 10 & 0.3 & 0.3 & 0.184 & 1.71 & 660 \\
\hline 3 & 25 & 15 & 0.4 & 0.4 & 0.225 & 2.18 & 665 \\
\hline 4 & 25 & 20 & 0.5 & 0.5 & 0.361 & 2.88 & 665 \\
\hline 5 & 25 & 25 & 0.6 & 0.6 & 0.484 & 3.67 & 665 \\
\hline 6 & 100 & 5 & 0.3 & 0.4 & 0.216 & 2.07 & 665 \\
\hline 7 & 100 & 10 & 0.4 & 0.5 & 0.428 & 3.99 & 665 \\
\hline 8 & 100 & 15 & 0.5 & 0.6 & 0.487 & 5.19 & 665 \\
\hline 9 & 100 & 20 & 0.6 & 0.2 & 0.18 & 1.25 & 649 \\
\hline 10 & 100 & 25 & 0.2 & 0.3 & 0.159 & 1.47 & 655 \\
\hline 11 & 200 & 5 & 0.4 & 0.6 & 0.416 & 5.57 & 665 \\
\hline 12 & 200 & 10 & 0.5 & 0.2 & 0.181 & 1.4 & 653 \\
\hline 13 & 200 & 15 & 0.6 & 0.3 & 0.258 & 1.85 & 663 \\
\hline 14 & 200 & 20 & 0.2 & 0.4 & 0.198 & 1.95 & 664 \\
\hline 15 & 200 & 25 & 0.3 & 0.5 & 0.291 & 2.98 & 665 \\
\hline 16 & 300 & 5 & 0.5 & 0.3 & 0.213 & 1.82 & 662 \\
\hline 17 & 300 & 10 & 0.6 & 0.4 & 0.321 & 2.64 & 665 \\
\hline 18 & 300 & 15 & 0.2 & 0.5 & 0.295 & 2.18 & 665 \\
\hline 19 & 300 & 20 & 0.3 & 0.6 & 0.347 & 2.92 & 665 \\
\hline 20 & 300 & 25 & 0.4 & 0.2 & 0.178 & 1.28 & 650 \\
\hline 21 & 400 & 5 & 0.6 & 0.5 & 0.541 & 5.27 & 665 \\
\hline 22 & 400 & 10 & 0.2 & 0.6 & 0.297 & 3.74 & 665 \\
\hline 23 & 400 & 15 & 0.3 & 0.2 & 0.139 & 1.14 & 646 \\
\hline 24 & 400 & 20 & 0.4 & 0.3 & 0.21 & 1.82 & 662 \\
\hline 25 & 400 & 25 & 0.5 & 0.4 & 0.294 & 2.86 & 665 \\
\hline
\end{tabular}

is included to ascertain if the results arise from residual errors or were they from the factors' contribution. The error contributions were $5.45 \%, 0.84 \%, 1.90 \%$ and $0.91 \%$ for damage, effective strain and stress and grey relational grade respectively. These error values indicate the percentage of the data that is due to error [36]. The error values were found to be very low to be considered. Twenty per cent should be the maximum value of the percentage error for good statistical data [37].

The strain per pass was the most significant factor that affected damage with a percentage contribution of $72.15 \%$ and a $p$ value of 0 . The outcome showed that damage would be highly affected by the slightest change in strain per pass. A 95\% confidence interval was used in this study. The other factor affecting damage was the friction coefficient with a percentage contribution of $20.1 \%$ and a $p$ value of 0.009 . It also meant that friction between dies and the workpieces played an important in determining the deformation. The plunger speed and temperature had $p$ values of 0.771 and 0.807 , respectively and had an insignificant contribution to damage of $1.22 \%$ and $1.08 \%$ respectively. Therefore, strain per and friction coefficient should be carefully minimised to reduce damage. For maximum effective strain, it was observed that strain per pass was the most significant having a P-value of 0 and a percentage contribution of $87.68 \%$. The friction coefficient had a percentage contribution of $7.95 \%$ and a P-value of 0 . The other parameters had little contribution to the effective strain. They indicated that strain per pass and friction coefficient are essential in inducing effective strain with strain per pass having the dominant effect. For maximum effective stress, strain per pass was the only significant factor with a contribution of $88.93 \%$ and a P-value of 0 . The contribution results of the strain per pass imply that the strain per pass should be significantly considered during deformation.

In the grey relational grade, ANOVA results showed that; the most significant parameters were; friction coefficient with a percentage contribution of $7.94 \%$ and a P-value of 0.001 . The strain per pass had a percentage contribution 
Table 4 Values of $\mathrm{S} / \mathrm{N}$ ratio, normalized $\mathrm{S} / \mathrm{N}$ and absolute difference

\begin{tabular}{|c|c|c|c|c|c|c|c|c|c|}
\hline \multirow[t]{2}{*}{ Exp no } & \multicolumn{3}{|l|}{$\mathrm{S} / \mathrm{N}$ ratios } & \multicolumn{3}{|c|}{ Normalization $\left(\mathrm{Z}_{\mathrm{ij}}\right)$} & \multicolumn{3}{|c|}{ Absolute difference $\left(\Delta_{\mathrm{oj}}\right)$} \\
\hline & Max. damage & $\begin{array}{l}\text { Max. effective } \\
\text { strain }\end{array}$ & $\begin{array}{l}\text { Max. effec- } \\
\text { tive stress } \\
\text { (MPa) }\end{array}$ & Max. damage & $\begin{array}{l}\text { Max. } \\
\text { effective } \\
\text { strain }\end{array}$ & $\begin{array}{l}\text { Max. effec- } \\
\text { tive stress } \\
(\mathrm{MPa})\end{array}$ & Max. damage & $\begin{array}{l}\text { Max. } \\
\text { effective } \\
\text { strain }\end{array}$ & $\begin{array}{l}\text { Max. effective } \\
\text { stress (MPa) }\end{array}$ \\
\hline 1 & 19.0935 & -0.3908 & 56.1236 & 0.0000 & 0.0000 & 0.0000 & 1.0000 & 1.0000 & 1.0000 \\
\hline 2 & 14.7036 & 4.6599 & 56.3909 & 0.3191 & 0.3299 & 0.8030 & 0.6809 & 0.6701 & 0.1970 \\
\hline 3 & 12.9563 & 6.7691 & 56.4564 & 0.4461 & 0.4677 & 1.0000 & 0.5539 & 0.5323 & 0.0000 \\
\hline 4 & 8.8499 & 9.1878 & 56.4564 & 0.7446 & 0.6257 & 1.0000 & 0.2554 & 0.3743 & 0.0000 \\
\hline 5 & 6.3031 & 11.2933 & 56.4564 & 0.9297 & 0.7633 & 1.0000 & 0.0703 & 0.2367 & 0.0000 \\
\hline 6 & 13.3109 & 6.3194 & 56.4564 & 0.4203 & 0.4384 & 1.0000 & 0.5797 & 0.5616 & 0.0000 \\
\hline 7 & 7.3711 & 12.0195 & 56.4564 & 0.8521 & 0.8107 & 1.0000 & 0.1479 & 0.1893 & 0.0000 \\
\hline 8 & 6.2494 & 14.3033 & 56.4564 & 0.9336 & 0.9599 & 1.0000 & 0.0664 & 0.0401 & 0.0000 \\
\hline 9 & 14.8945 & 1.9382 & 56.2449 & 0.3052 & 0.1521 & 0.3644 & 0.6948 & 0.8479 & 0.6356 \\
\hline 10 & 15.9721 & 3.3463 & 56.3248 & 0.2269 & 0.2441 & 0.6046 & 0.7731 & 0.7559 & 0.3954 \\
\hline 11 & 7.6181 & 14.9171 & 56.4564 & 0.8341 & 1.0000 & 1.0000 & 0.1659 & 0.0000 & 0.0000 \\
\hline 12 & 14.8464 & 2.9226 & 56.2983 & 0.3087 & 0.2164 & 0.5248 & 0.6913 & 0.7836 & 0.4752 \\
\hline 13 & 11.7676 & 5.3434 & 56.4303 & 0.5325 & 0.3746 & 0.9214 & 0.4675 & 0.6254 & 0.0786 \\
\hline 14 & 14.0667 & 5.8007 & 56.4434 & 0.3654 & 0.4045 & 0.9607 & 0.6346 & 0.5955 & 0.0393 \\
\hline 15 & 10.7221 & 9.4843 & 56.4564 & 0.6085 & 0.6451 & 1.0000 & 0.3915 & 0.3549 & 0.0000 \\
\hline 16 & 13.4324 & 5.2014 & 56.4172 & 0.4115 & 0.3653 & 0.8820 & 0.5885 & 0.6347 & 0.1180 \\
\hline 17 & 9.8699 & 8.4321 & 56.4564 & 0.6704 & 0.5764 & 1.0000 & 0.3296 & 0.4236 & 0.0000 \\
\hline 18 & 10.6036 & 6.7691 & 56.4564 & 0.6171 & 0.4677 & 1.0000 & 0.3829 & 0.5323 & 0.0000 \\
\hline 19 & 9.1934 & 9.3077 & 56.4564 & 0.7196 & 0.6336 & 1.0000 & 0.2804 & 0.3664 & 0.0000 \\
\hline 20 & 14.9916 & 2.1442 & 56.2583 & 0.2982 & 0.1656 & 0.4046 & 0.7018 & 0.8344 & 0.5954 \\
\hline 21 & 5.3361 & 14.4362 & 56.4564 & 1.0000 & 0.9686 & 1.0000 & 0.0000 & 0.0314 & 0.0000 \\
\hline 22 & 10.5449 & 11.4574 & 56.4564 & 0.6214 & 0.7740 & 1.0000 & 0.3786 & 0.2260 & 0.0000 \\
\hline 23 & 17.1397 & 1.1381 & 56.2047 & 0.1420 & 0.0999 & 0.2435 & 0.8580 & 0.9001 & 0.7565 \\
\hline 24 & 13.5556 & 5.2014 & 56.4172 & 0.4025 & 0.3653 & 0.8820 & 0.5975 & 0.6347 & 0.1180 \\
\hline 25 & 10.6331 & 9.1273 & 56.4564 & 0.6150 & 0.6218 & 1.0000 & 0.3850 & 0.3782 & 0.0000 \\
\hline
\end{tabular}

Fig. 4 The scree plot of damage, effective strain and stress

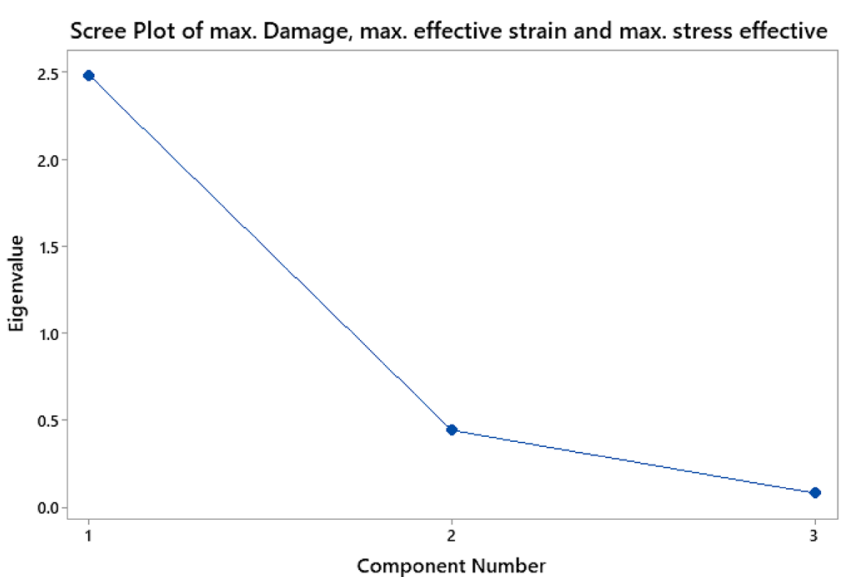

of $88.93 \%$ and a P-value of 0 . This implied that both friction coefficient and strain per pass highly affected the process's output. The temperature and the plunger speed least affect the MDF process.

\begin{tabular}{llll}
\hline Eigenvalue & 2.4842 & 0.4390 & 0.0768 \\
\hline Proportion & 0.828 & 0.146 & 0.026 \\
Cumulative & 0.828 & 0.974 & 1.000 \\
\hline
\end{tabular}

SN Applied Sciences 
Table 6 Table of grey relational coefficient values and their respective grey grade

\begin{tabular}{|c|c|c|c|c|}
\hline \multirow[t]{2}{*}{ Exp. no } & \multicolumn{3}{|c|}{ Grey relational coefficient } & \multirow{2}{*}{$\begin{array}{l}\text { Grey relational } \\
\text { grade (GRG) }\end{array}$} \\
\hline & Max. damage & $\begin{array}{l}\text { Max. } \\
\text { strain- } \\
\text { effective }\end{array}$ & $\begin{array}{l}\text { Max. stress- } \\
\text { effective } \\
(\mathrm{MPa})\end{array}$ & \\
\hline 1 & 0.3750 & 0.0909 & 0.2308 & 0.2322 \\
\hline 2 & 0.4684 & 0.1299 & 0.6037 & 0.4007 \\
\hline 3 & 0.5200 & 0.1582 & 1.0000 & 0.5594 \\
\hline 4 & 0.7014 & 0.2109 & 1.0000 & 0.6374 \\
\hline 5 & 0.8951 & 0.2970 & 1.0000 & 0.7307 \\
\hline 6 & 0.5086 & 0.1511 & 1.0000 & 0.5533 \\
\hline 7 & 0.8022 & 0.3457 & 1.0000 & 0.7160 \\
\hline 8 & 0.9004 & 0.7138 & 1.0000 & 0.8714 \\
\hline 9 & 0.4634 & 0.1055 & 0.3207 & 0.2965 \\
\hline 10 & 0.4370 & 0.1168 & 0.4314 & 0.3284 \\
\hline 11 & 0.7834 & 1.0000 & 1.0000 & 0.9278 \\
\hline 12 & 0.4647 & 0.1132 & 0.3870 & 0.3216 \\
\hline 13 & 0.5621 & 0.1379 & 0.7924 & 0.4974 \\
\hline 14 & 0.4860 & 0.1438 & 0.8842 & 0.5047 \\
\hline 15 & 0.6051 & 0.2198 & 1.0000 & 0.6083 \\
\hline 16 & 0.5048 & 0.1361 & 0.7177 & 0.4529 \\
\hline 17 & 0.6455 & 0.1910 & 1.0000 & 0.6121 \\
\hline 18 & 0.6104 & 0.1582 & 1.0000 & 0.5895 \\
\hline 19 & 0.6815 & 0.2144 & 1.0000 & 0.6320 \\
\hline 20 & 0.4609 & 0.1070 & 0.3350 & 0.3010 \\
\hline 21 & 1.0000 & 0.7610 & 1.0000 & 0.9203 \\
\hline 22 & 0.6131 & 0.3067 & 1.0000 & 0.6400 \\
\hline 23 & 0.4115 & 0.1000 & 0.2840 & 0.2652 \\
\hline 24 & 0.5011 & 0.1361 & 0.7177 & 0.4516 \\
\hline 25 & 0.6091 & 0.2091 & 1.0000 & 0.6061 \\
\hline
\end{tabular}

\subsection{Confirmatory simulation}

The confirmatory simulations were carried out at the optimum results. The results obtained were recorded in Table 9. From the table, the least damage was 0.111 , recorded when a simulation was carried out at $\mathrm{S} / \mathrm{N}$ optimised result for damage. In comparison, the most excellent effective strain was 5.57, observed from optimised grey relational grade data.

Figure 6 shows the contours of damage and effective strain for sliced samples at optimum conditions. The damage distribution results demonstrated that damage was more on the sample's surface than in the innermost parts of the material. The edges and corners experienced the most damage. The damage resulted from the increased strains due to the high loads and abrasive wear of the surfaces. The other factor that caused the damage was friction. The strain contour showed that along the edges, the strains increased. The central region experienced low strains. Although the multi-directional forging achieves a certain level of homogeneity, there is still a need to enhance the distribution of the stresses and the strain.

\section{Discussion}

In Fig. 5, the strain per pass has a very steep slope which shows that a slight change in the strain per pass highly affects the MDF process. Strain per pass above 0.5 influences the optimal results for damage, effective strain and stress. The high dependence of the output parameters to the strain per pass is attributed to its contribution to the evolution and refinement of grains in materials: the smaller the grains' size, the greater the effective strain and stress. However, a rapid formation of the new small grains results in misorientation causing microstructural damages [38]. During the MDF, deformation bands and micro shear bands are formed in different directions, intersecting each other, resulting in continuous grain fragmentation. Further deformations increase the fragmentations and misorientation at the borders, and nearly refined material with equiaxed grains are produced at high strains [39]. As uniaxial compression is applied to the material continuously the misorientation at the boundaries intensifies and the spacing between the grains decreases. The accumulation of strains causes microstructural non-uniformities to evolve gradually during each compression pass [9].

When the MDF was conducted for strain per pass above 0.3 , the effective stress increased rapidly until the maximum value of $665 \mathrm{Mpa}$ was attained, as shown in Table 4. The maximum effective stress indicates the dislocation density increased and the ultrafine grains were formed [40]. However, when using strain per pass of 0.3, the temperatures must be high and the friction coefficient above 0.4 to get the effective stress above $660 \mathrm{MPa}$. Temperature highly influences the product's final quality $[9,41,42]$. Zhao et al. reported that when an aluminium alloy is heated, the grain structure does not change until the temperature gets to about $350^{\circ} \mathrm{C}$. At this temperature, the grains at the boundaries start to form new grains rapidly until a new undistorted grain structure is developed, replacing the old one, a process called recrystallization. The recrystallized aluminium develops different mechanical properties from the former; for example, hardness for such materials decrease, resulting in more damage. Additionally, the tensile strength decreases with an increase in temperature while the ductility and the effective strain increase [43].

The effect of the die speed and friction coefficient can be observed in Table 3. An increase in the plunger speed resulted in more damage. This can be attributed to the reduced cooling during the process, resulting in increased 
a

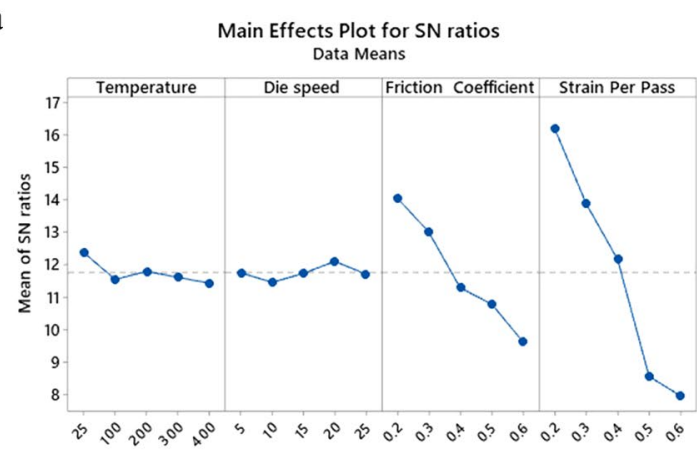

Signal-to-noise: Smaller is better

c

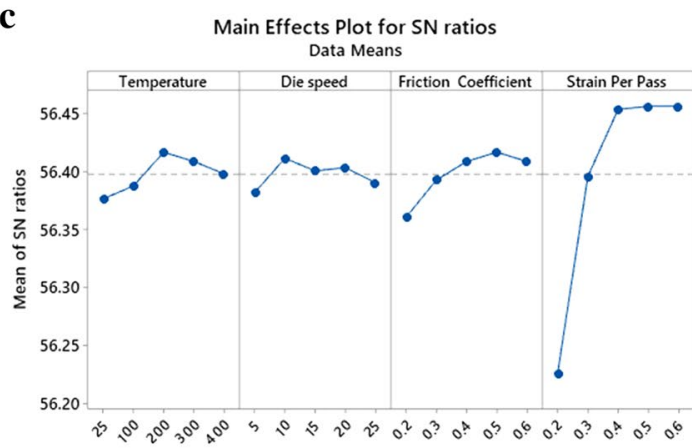

Signal-to-noise: Larger is better

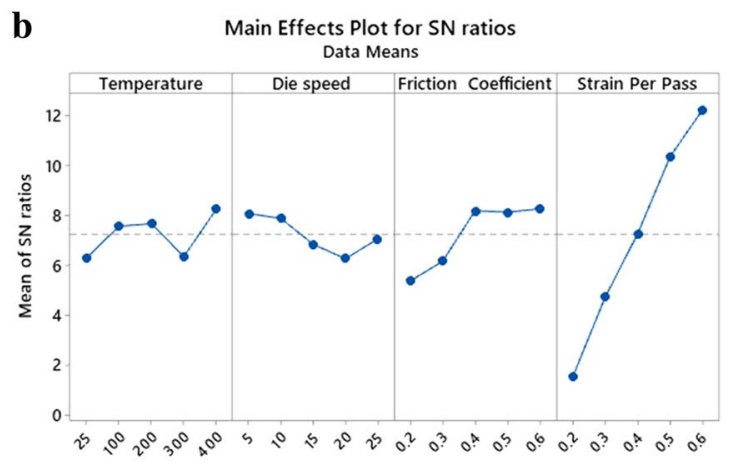

Signal-to-noise: Larger is better

d

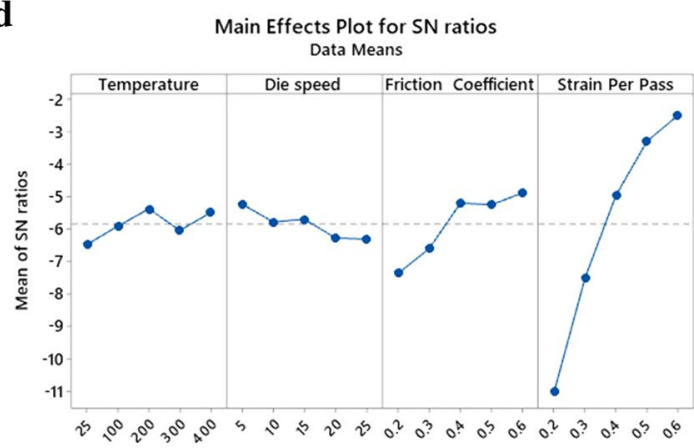

Signal-to-noise: Larger is better

Fig. 5 Main effects plot for S/N ratios for maximum damage (a), maximum effective strain (b), maximum effective stress (c) and GRG (d)

Table 7 Optimum conditions for the MDF process as per the signal to noise ratio

\begin{tabular}{lllll}
\hline Factor & \multicolumn{3}{l}{ Single response optimisation } & \\
\cline { 2 - 5 } & $\begin{array}{l}\text { Max. damage } \\
(\mathrm{S} / \mathrm{N})\end{array}$ & $\begin{array}{l}\text { Max. strain effec- } \\
\text { tive }(\mathrm{S} / \mathrm{N})\end{array}$ & $\begin{array}{l}\text { Max. stress effec- } \\
\text { tive }(\mathrm{S} / \mathrm{N})\end{array}$ & Grade $(\mathrm{S} / \mathrm{N})$ \\
\hline Temperature $\left({ }^{\circ} \mathrm{C}\right)$ & 25 & 400 & 200 & 200 \\
Plunger speed $(\mathrm{mm} / \mathrm{s})$ & 20 & 5 & 10 & 5 \\
Friction coefficient & 0.2 & 0.6 & 0.5 & 0.4 \\
Strains per pass & 0.2 & 0.6 & 0.5 & 0.6 \\
\hline
\end{tabular}

internal temperature and increased internal stress in the workpiece [44]. Considering the friction coefficient, an increase in friction coefficient resulted in increased damage but better effective strain. The friction coefficient is the ratio of the resisting force to the normal force. Temperature and deformation speed are other factors that affect the friction at the interface during a forging process [45]. The MDF utilizes compressive forces from the high loads and speeds, resulting in abrasive wear. When surfaces are excessively abrased, failure initiation is likely to start at the worn-out points. However, friction during the forging process improves the strain and stress distribution and the material flow, thus determining the product quality [46].
In Fig. 6a, b, an inhomogeneous distribution of damage and the effective strain was observed; this was due to the inhomogeneous distribution of nanoparticles [47]. The inhomogeneities of particles and material properties result from the inhomogeneous distribution of strain in the sample during compression. Previous studies indicated that strains and temperature immensely affected the material's structure homogeneity $[48,49]$. However, the change of axis of deformation during MDF and higher strain per pass led to the development of uniform distribution of strain, stress and damage [50,51], observed in Fig. 6b, c. 
Table 8 Analysis of variance for transformed grade response

\begin{tabular}{lllll}
\hline Factor & $\begin{array}{l}\text { Degree of } \\
\text { freedom }\end{array}$ & Sum squares & Mean squares & F-value $p$ value $\%$ Contribution
\end{tabular}

\begin{tabular}{lcccrll}
\hline (a) Damage & & & & & & \\
Temperature & 4 & 0.00358 & 0.000895 & 0.39 & 0.807 & 1.08 \\
Plunger speed & 4 & 0.004072 & 0.001018 & 0.45 & 0.771 & 1.22 \\
Friction coefficient & 4 & 0.066898 & 0.016725 & 7.38 & 0.009 & 20.10 \\
Strain per pass & 4 & 0.240078 & 0.06002 & 26.48 & 0 & 72.15 \\
Error & 8 & 0.018134 & 0.002267 & & & 5.45 \\
Total & 24 & 0.332762 & & & & 100 \\
(b) Maximum effective strain & & & & & \\
Temperature & 4 & 0.02907 & 0.007267 & 5.41 & 0.021 & 2.28 \\
Plunger speed & 4 & 0.01594 & 0.003984 & 2.97 & 0.089 & 1.25 \\
Friction coefficient & 4 & 0.10126 & 0.025315 & 18.84 & 0 & 7.95 \\
Strain per pass & 4 & 1.11735 & 0.279339 & 207.89 & 0 & 87.68 \\
Error & 8 & 0.01075 & 0.001344 & & & 0.84 \\
Total & 24 & 1.27437 & & & & 100 \\
(c) Maximum effective & stress & & & & & \\
Temperature & 4 & 4.887 & 1.222 & 0.88 & 0.515 & 0.84 \\
Plunger speed & 4 & 4.07 & 1.017 & 0.74 & 0.593 & 0.70 \\
Friction coefficient & 4 & 11.963 & 2.991 & 2.16 & 0.164 & 2.06 \\
Strain per pass & 4 & 549.16 & 137.29 & 99.35 & 0 & 94.50 \\
Error & 8 & 11.055 & 1.382 & & & 1.90 \\
Total & 24 & 581.136 & & & & 100 \\
(d) Grey relational grade & 4 & & & & & \\
Temperature & 4 & 0.02949 & 0.007373 & 3.25 & 0.073 & 1.48 \\
Plunger speed & 4 & 0.01463 & 0.003658 & 1.61 & 0.262 & 0.73 \\
Friction coefficient & 4 & 0.15812 & 0.039530 & 17.40 & 0.001 & 7.94 \\
Strain per pass & 4 & 1.77050 & 0.442625 & 194.80 & 0.000 & 88.93 \\
Error & 8 & 0.01818 & 0.002272 & & & 0.91 \\
Total & 24 & 0.332762 & & & & 100.00 \\
\hline & & & & & & \\
\hline & 4 & & & & & \\
\hline
\end{tabular}

Table 9 Optimum conditions for the MDF process and their output responses

\begin{tabular}{|c|c|c|c|c|}
\hline \multirow[t]{2}{*}{ Factor/response } & \multicolumn{3}{|c|}{ Single response optimisation using $\mathrm{S} / \mathrm{N}$} & \multirow{2}{*}{$\begin{array}{l}\text { Grey rela- } \\
\text { tional grade } \\
(\mathrm{S} / \mathrm{N})\end{array}$} \\
\hline & Max. damage & $\begin{array}{l}\text { Max. strain } \\
\text { effective }\end{array}$ & $\begin{array}{l}\text { Max. stress } \\
\text { effective }\end{array}$ & \\
\hline Temperature $\left({ }^{\circ} \mathrm{C}\right)$ & 25 & 400 & 200 & 200 \\
\hline Plunger speed (mm/s) & 20 & 5 & 10 & 5 \\
\hline Friction coefficient $(\mu)$ & 0.2 & 0.6 & 0.5 & 0.4 \\
\hline Strains per pass & 0.2 & 0.6 & 0.5 & 0.6 \\
\hline Max. damage & 0.1111 & 0.451 & 0.363 & 0.416 \\
\hline Max. strain effective & 0.956 & 5.05 & 2.94 & 5.57 \\
\hline Max stress effective (MPa) & 640 & 665 & 665 & 665 \\
\hline
\end{tabular}

\section{Conclusion}

In this study, the multi-directional forging of AA 7075 was studied. The principal objective was to optimise the MDF process based on the significant process parameters. The $D_{E F O R M}{ }^{\mathrm{TM}} 3 \mathrm{D}$ was used for simulation. The effects of varying the process input parameters (plunger speed, temperature, friction coefficient and strain per pass) on maximum damage, maximum effective stress and maximum effective strain were studied. The signal-to-noise ratio identified the optimum conditions for each response to be as follows; damage, the optimum temperature was $25^{\circ} \mathrm{C}$, the plunger speed, $20 \mathrm{~mm} / \mathrm{s}$, the friction coefficient, 0.2 and the strain per pass, 0.2 . These conditions resulted in the least damage of 0.111 . For maximum 
Fig. 6 Results of a damage, $\mathbf{b}$ effective strain and c effective stress for a sliced sample, simulated at a temperature of $200^{\circ} \mathrm{C}$, friction coefficient of 0.4 , strain per pass of 0.6 and plunger speed of $5 \mathrm{~mm} / \mathrm{s}$
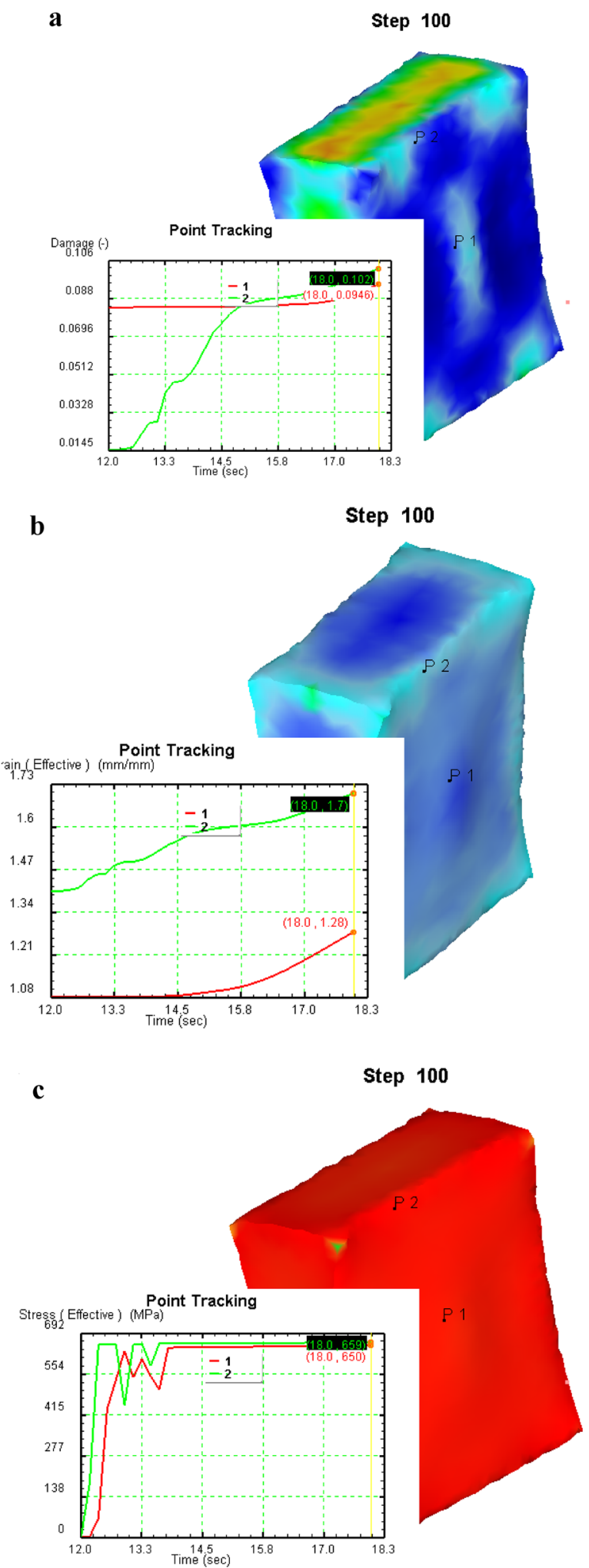

Damage 0.416

0.278

0.139

0.0000463 $0.00195 \mathrm{Min}$

$70.416 \mathrm{Max}$

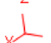

Strain - Effective ( $\mathrm{mm} / \mathrm{mm}$ )

5.57

3.89

2.21

0.527

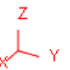

Stress - Effective (MPa)

665

444

222

0.000

357 Min

665 Max effective strain, the optimal values identified were; temperature, $400{ }^{\circ} \mathrm{C}$, plunger speed, $5 \mathrm{~mm} / \mathrm{s}$, friction coefficient, 0.6 and the strain per pass at a point of 0.6. Finally, for maximum stress-effective, the values were; temperature, $200^{\circ} \mathrm{C}$, plunger speed, $10 \mathrm{~mm} / \mathrm{s}$, the friction coefficient, 0.5 and the strain per pass, 0.5. From the ANOVA, it was noted that the strain per pass is the most crucial input that affects damage, effective strain and stress. Optimisation using the grey relation analysis 
produced a material with a damage value of 0.416 , an effective strain of 5.57 and effective stress of $665 \mathrm{Mpa}$.

The current study was limited to simulation. However, this study brings a better understanding of the MDF process and the optimisation of the process parameters when processing AA 7075. The results will be significant in guiding the choice of MDF parameters not only for AA 7075 but also for other metal alloys. The results will go a long way in assisting manufacturers and researchers in developing AA 7075 with better mechanical properties. The AA 7075 with improved mechanical properties can be applied in the automobile, aerospace and construction industries. This research, therefore, contributes immense knowledge to the quality production of high-strength AA 7075.

In future work, further optimisation results of AA 7075 can be obtained if the studies focus on analyzing the alloy's chemical variation, its spatial variations of the stresses and strains in different metal atoms, grain structure, and boundaries dislocation distribution. Further research should also be carried out on other hard-to-machine metals.

\section{Declaration}

Conflict of interest The authors declare that they have no conflict of interest.

Open Access This article is licensed under a Creative Commons Attribution 4.0 International License, which permits use, sharing, adaptation, distribution and reproduction in any medium or format, as long as you give appropriate credit to the original author(s) and the source, provide a link to the Creative Commons licence, and indicate if changes were made. The images or other third party material in this article are included in the article's Creative Commons licence, unless indicated otherwise in a credit line to the material. If material is not included in the article's Creative Commons licence and your intended use is not permitted by statutory regulation or exceeds the permitted use, you will need to obtain permission directly from the copyright holder. To view a copy of this licence, visit http://creativecommons. org/licenses/by/4.0/.

\section{Appendix}

Simulation images of effective stress and strain for experiments 1-12.
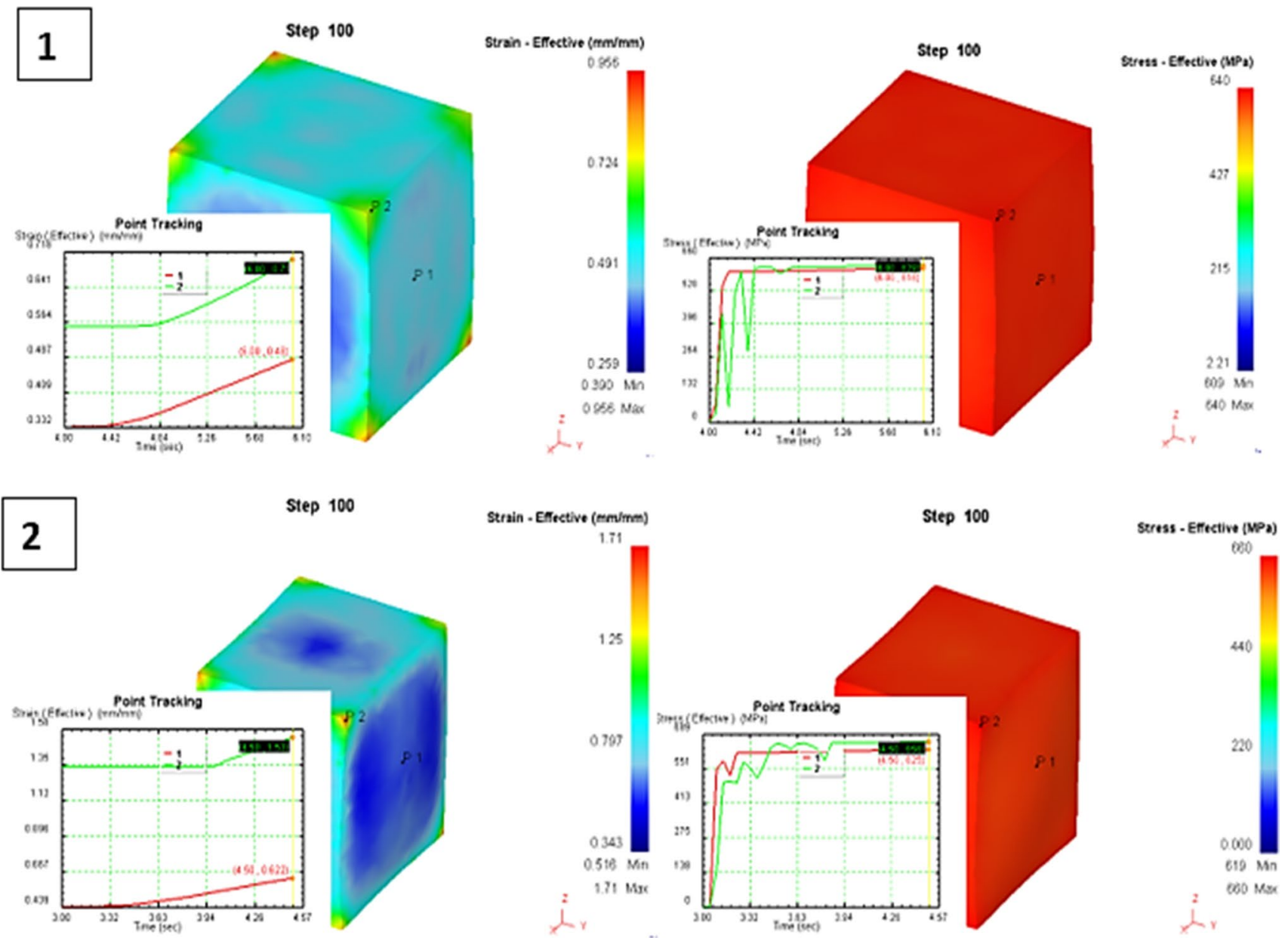

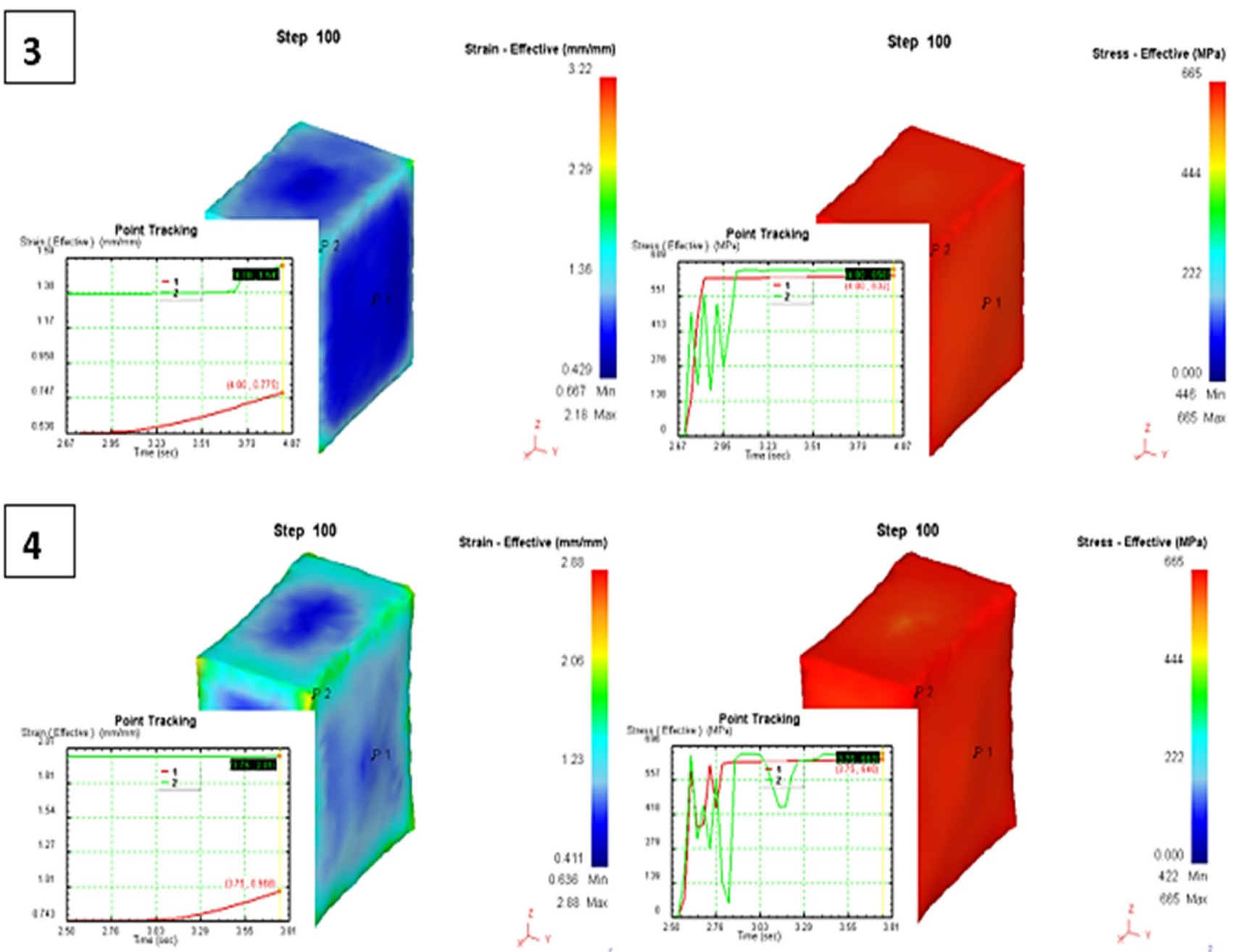


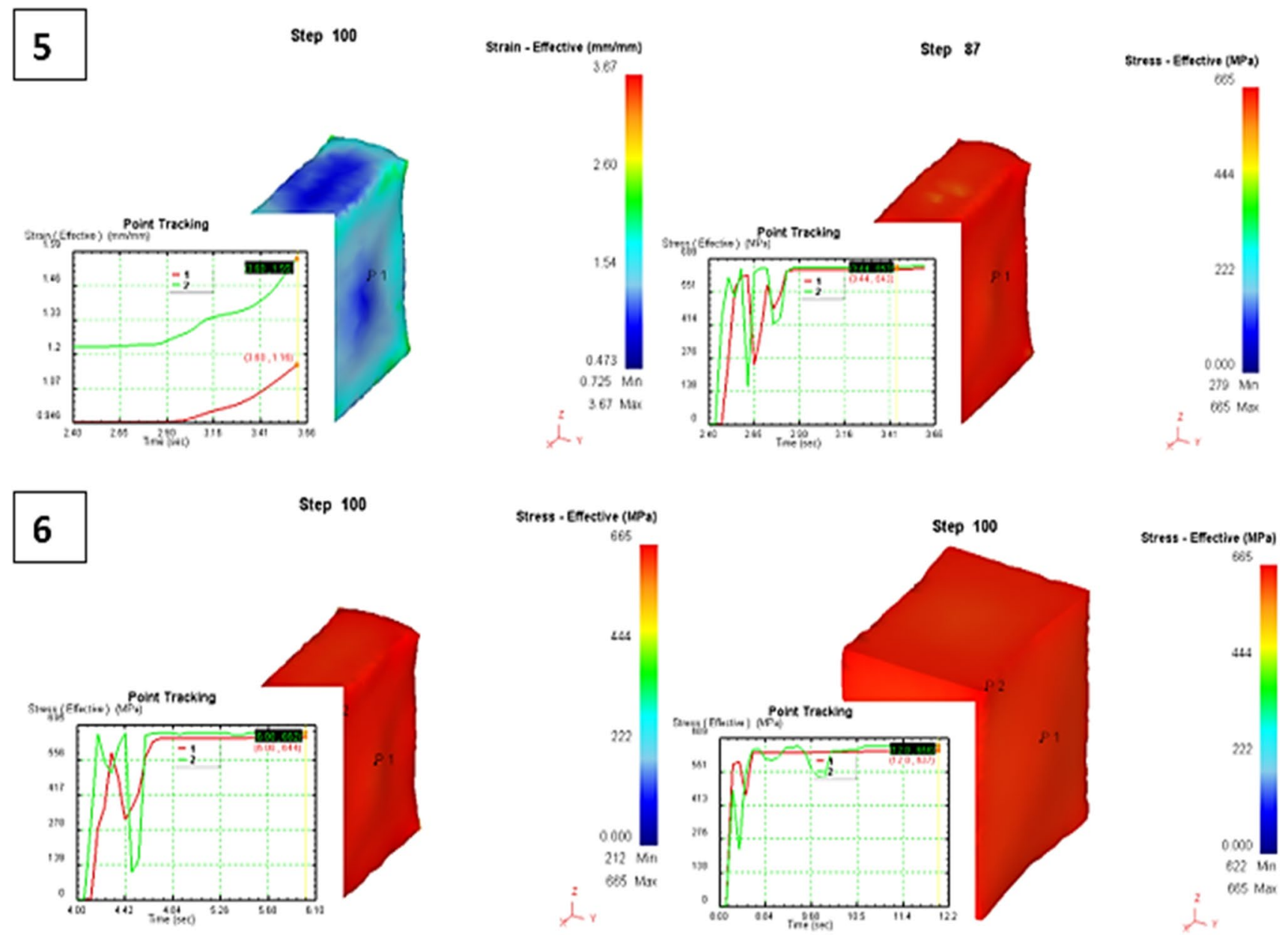



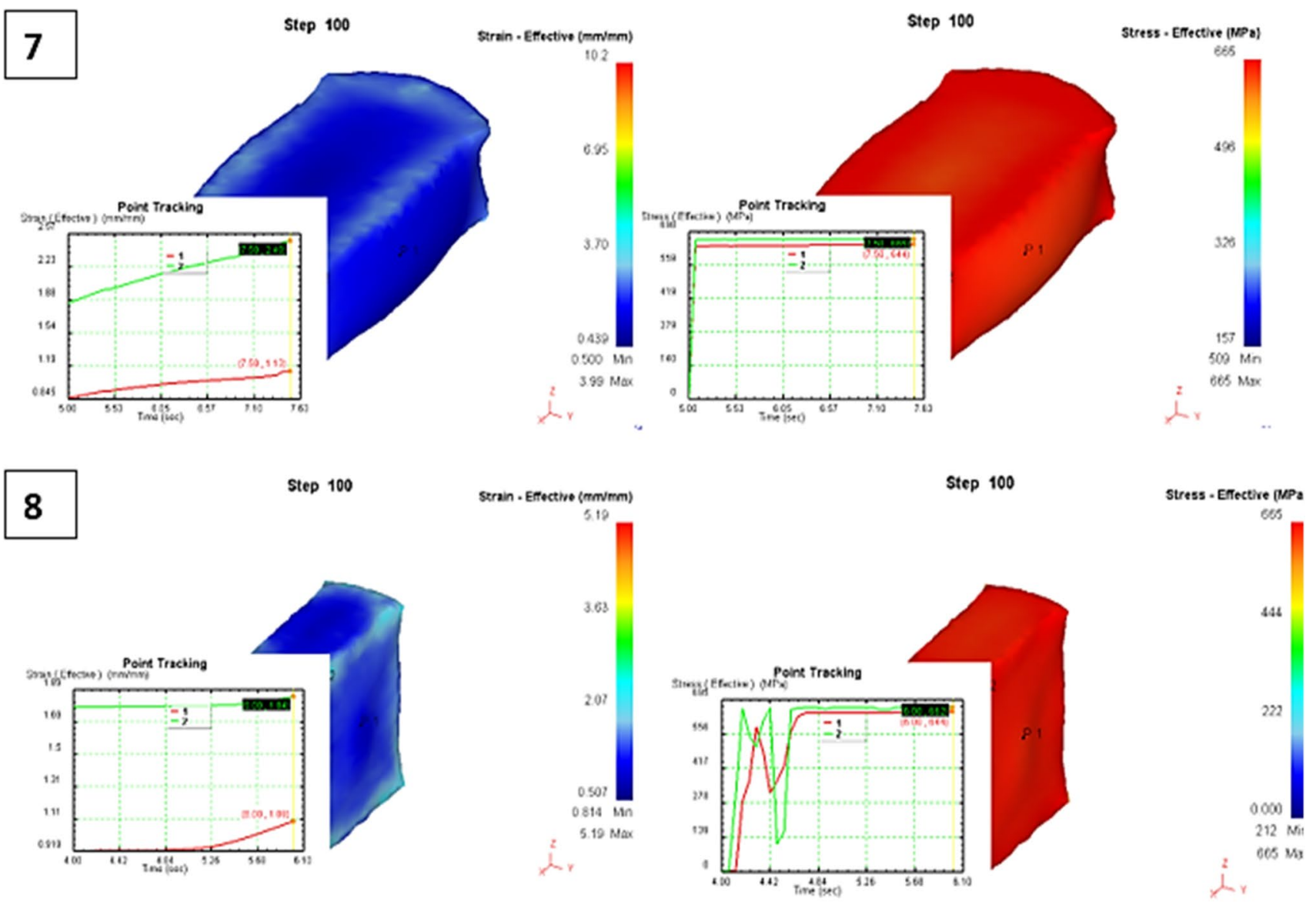

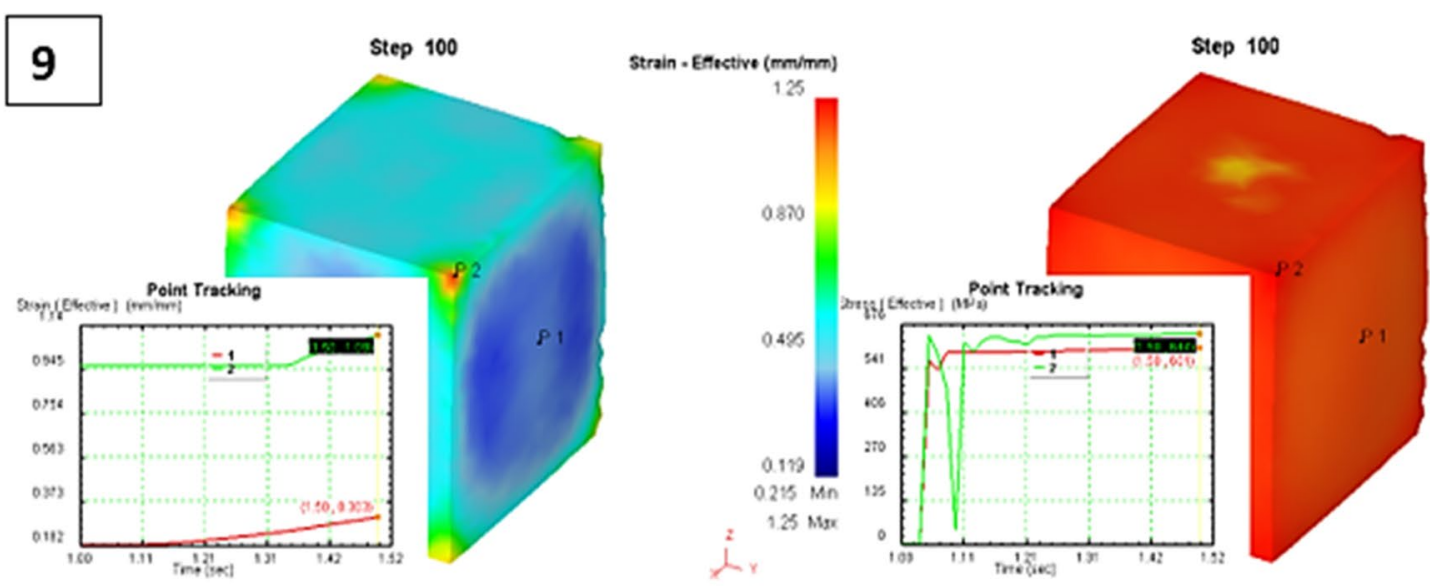

Stress - Efroctive (uPa)
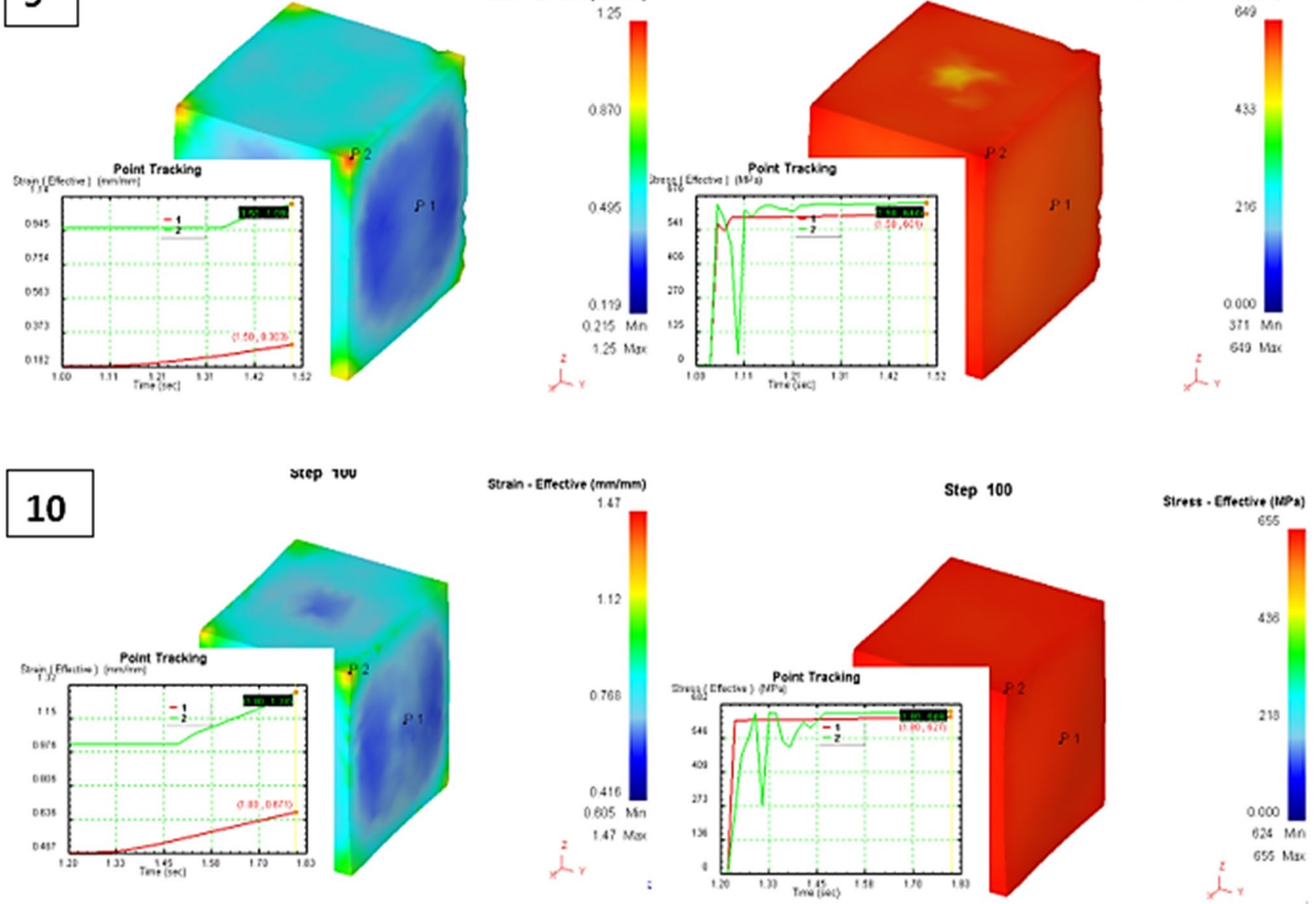


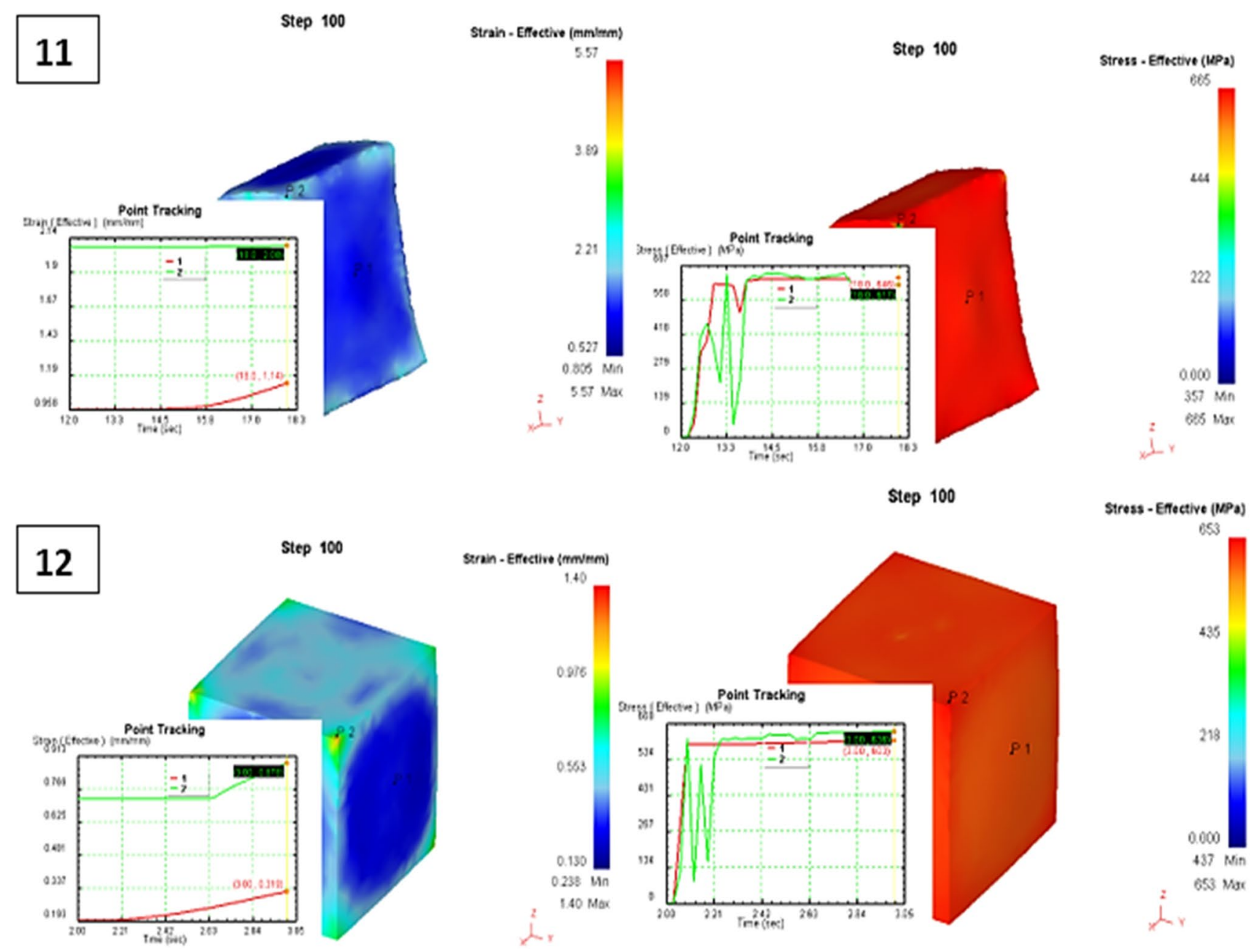

\section{References}

1. Li J, Liu J, Cui Z (2015) Microstructures and mechanical properties of AZ61 magnesium alloy after isothermal multidirectional forging with increasing strain rate. Mater Sci Eng A 643:32-36. https://doi.org/10.1016/j.msea.2015.07.028

2. Kaibyshev OA (2001) Grain refinement in commercial alloys due to high plastic deformations and phase transformations. J Mater Process Technol 117(3):300-306. https://doi.org/10.1016/s09240136(01)00784-1

3. Zhao Z, Chen Q, Hu C, Shu D (2009) Microstructure and mechanical properties of SPD-processed an as-cast AZ91D+Y magnesium alloy by equal channel angular extrusion and multi-axial forging. Mater Des 30(10):4557-4561. https://doi.org/10.1016/j. matdes.2009.04.023

4. Noda M, Hirohashi M, Funami K (2003) Low temperature superplasticity and its deformation mechanism in grain refinement of $\mathrm{Al}-\mathrm{Mg}$ alloy by multi-axial alternative forging. Mater Trans 44(11):2288-2297. https://doi.org/10.2320/matertrans.44.2288

5. Kingkam W, Li N, Zhang HX, Zhao CZ (2017) Hot deformation behavior of high strength low alloy steel by thermo mechanical

simulator and finite element method. IOP Conf Ser Mater Sci Eng 205:12001. https://doi.org/10.1088/1757-899x/205/1/012001

6. Stemler PMA et al (2019) Mechanical behavior and microstructures of aluminum in the multi-axial compression (MAC) with and without specimen re-machining. Mater Lett 237:84-87. https://doi.org/10.1016/j.matlet.2018.11.081

7. Zhu Q, Li L, Ban C, Zhao Z, Zuo Y, Cui J (2014) Structure uniformity and limits of grain refinement of high purity aluminum during multi-directional forging process at room temperature. Trans Nonferr Met Soc China 24(5):1301-1306. https://doi.org/ 10.1016/s1003-6326(14)63192-7

8. Miura H, Nakamura W, Kobayashi M (2014) Room-temperature multi-directional forging of AZ80Mg alloy to induce ultrafine grained structure and specific mechanical properties. Procedia Eng 81(10-11):534-539. https://doi.org/10.1016/j.proeng.2014. 10.035

9. Kishchik MS, Mikhaylovskaya AV, Kotov AD, Mosleh AO, AbuShanab WS, Portnoy VK (2018) Effect of multidirectional forging on the grain structure and mechanical properties of the $\mathrm{Al}-\mathrm{Mg}-\mathrm{Mn}$ alloy. Materials. https://doi.org/10.3390/ma11112166

10. Xing J, Yang XY, Miura H, Sakai T (2005) Grain refinement in magnesium alloy AZ31 during multidirectional forging under 
decreasing temperature conditions. MSF 488-489:597-600. https://doi.org/10.4028/www.scientific.net/MSF.488-489.597

11. Mineta $T$, Hasegawa $K$, Sato $H$ (2020) High strength and plastic deformability of $\mathrm{Mg}-\mathrm{Li}-\mathrm{Al}$ alloy with dual $\mathrm{BCC}$ phase produced by a combination of heat treatment and multi-directional forging in channel die. Mater Sci Eng A 773:138867. https://doi.org/ 10.1016/j.msea.2019.138867

12. Pan LF, Chen L, Yan WL (2014) High strength and ductility in multi-directional forged wrought aluminum alloys. AMR 1064:26-31. https://doi.org/10.4028/www.scientific.net/AMR. 1064.26

13. Zhang R, Li Z, Sheng X, Gao Y, Lei Q (2020) Grain refinement and mechanical properties improvements in a high strength $\mathrm{Cu}-\mathrm{Ni}-\mathrm{Si}$ alloy during multidirectional forging. Fusion Eng Des 159(147):111766. https://doi.org/10.1016/j.fusengdes.2020. 111766

14. Mohapatra SK, Maity KP (2016) Parametric optimization of simulated extrusion of square to square section through linear converging die. IOP Conf Ser Mater Sci Eng 115:12031. https:// doi.org/10.1088/1757-899X/115/1/012031

15. Anon A (2014) DEFORM_V11.0_(PC)_Documentation

16. Chyła P, Pater Z, Tomczak J (2016) Numerical analysis of a rolling process for producing steel balls using helical rolls. Arch Metall Mater 61(2):485-492. https://doi.org/10.1515/amm-2016-0085

17. Konstantin S (2014) Development of software for simulation of forming forgings. Procedia Eng 81:437-443. https://doi.org/10. 1016/j.proeng.2014.10.019

18. Zhang ZJ, Dai GZ, Wu SN, Dong LX, Liu LL (2009) Simulation of $42 \mathrm{CrMo}$ steel billet upsetting and its defects analyses during forming process based on the software DEFORM-3D. Mater Sci Eng A 499(1-2):49-52. https://doi.org/10.1016/j.msea.2007.11. 135

19. Deepak Kumar S, Karthik D, Mandal A, Pavan Kumar JSR (2017) Optimization of thixoforging process parameters of A356 alloy using Taguchi's experimental design and DEFORM simulation. Mater Today Proc 4(9):9987-9991. https://doi.org/10.1016/j. matpr.2017.06.307

20. Ju-Long D (1982) Control problems of grey systems. Syst Control Lett 1(5):288-294. https://doi.org/10.1016/s0167-6911(82) 80025-x

21. Liu S, Forrest J, Yang Y (2012) A brief introduction to grey systems theory. Grey Syst Theory Appl 2(2):89-104. https://doi.org/ $10.1108 / 20439371211260081$

22. Xie N (2017) Explanations about grey information and framework of grey system modeling. Grey Syst Theory Appl 7(2):179193. https://doi.org/10.1108/gs-05-2017-0012

23. Manohara R, Harinath A (2019) Application of taguchi method for optimization of process parameters in drilling operation. IJTSRD 3(4):1052-1057. https://doi.org/10.31142/ijtsrd24003.

24. Wei J, Jiang S, Chen Z, Liu C (2020) Increasing strength and ductility of a Mg-9Al alloy by dynamic precipitation assisted grain refinement during multi-directional forging. Mater Sci Eng A 780:139192. https://doi.org/10.1016/j.msea.2020.139192

25. Musonda V, Akinlabi ET (2018) Three-dimensional simulation of a single pass hot rolling of carbon steel: case of instabilities in steady state region. IOP Conf Ser Mater Sci Eng 423:12162. https://doi.org/10.1088/1757-899X/423/1/012162

26. Weber S, Montero J, Bleckmann M, Paetzold K (2020) A comparison of layered tetrahedral and cartesian meshing in additive manufacturing simulation. Procedia CIRP 91:522-527. https:// doi.org/10.1016/j.procir.2020.02.209

27. Dubey AK, Yadava V (2008) Multi-objective optimization of $\mathrm{Nd}$ :YAG laser cutting of nickel-based superalloy sheet using orthogonal array with principal component analysis. Opt Lasers
Eng 46(2):124-132. https://doi.org/10.1016/j.optlaseng.2007.08. 011

28. Viswanathan R, Ramesh S, Maniraj S, Subburam V (2020) Measurement and multi-response optimization of turning parameters for magnesium alloy using hybrid combination of TaguchiGRA-PCA technique. Measurement 159(5):107800. https://doi. org/10.1016/j.measurement.2020.107800

29. Kaushik N, Singhal S (2018) Hybrid combination of Taguchi-GRAPCA for optimization of wear behavior in AA6063/SiC p matrix composite. Prod Manuf Res 6(1):171-189. https://doi.org/10. 1080/21693277.2018.1479666

30. Torki ME, Benzerga AA (2018) A mechanism of failure in shear bands. Extreme Mech Lett 23:67-71. https://doi.org/10.1016/j. eml.2018.06.008

31. White GN, Drucker DC (1950) Effective stress and effective strain in relation to stress theories of plasticity. J Appl Phys 21(10):1013-1021. https://doi.org/10.1063/1.1699434

32. Khan ZA, Siddiquee AN, Khan NZ, Khan U, Quadir GA (2014) Multi response optimization of wire electrical discharge machining process parameters using Taguchi based grey relational analysis. Procedia Mater Sci 6(4):1683-1695. https://doi.org/ 10.1016/j.mspro.2014.07.154

33. Mahmoudi A, Javed SA, Liu S, Deng X (2020) Distinguishing coefficient driven sensitivity analysis of gra model for intelligent decisions: application in project management. Technol Econ Dev Econ 26(3):621-641. https://doi.org/10.3846/tede. 2020.11890

34. Achuthamenon SP, Ramakrishnasamy R, Palaniappan G (2018) Taguchi grey relational analysis for multi-response optimization of wear in co-continuous composite. Materials. https://doi.org/ 10.3390/ma11091743

35. Kuo Y, Yang T, Huang G-W (2008) The use of a grey-based Taguchi method for optimizing multi-response simulation problems. Eng Optim 40(6):517-528. https://doi.org/10.1080/0305215070 1857645

36. Scott I, Mazhindu D (eds) (2005) Statistics for health care professionals: errors and ANOVAs. Sage, London

37. Mohamed OA, Masood SH, Bhowmik JL (2016) Mathematical modeling and FDM process parameters optimization using response surface methodology based on Q-optimal design. Appl Math Model 40(23-24):10052-10073. https://doi.org/10. 1016/j.apm.2016.06.055

38. Sitdikov O, Sakai T, Goloborodko A, Miura H, Kaibyshev R (2004) Effect of pass strain on grain refinement in 7475 Al alloy during hot multidirectional forging. Mater Trans 45(7):2232-2238. https://doi.org/10.2320/matertrans.45.2232

39. Nakashima I, Horita Z, Nemoto M, Langdon TG (1998) Influence of channel angle on the development of ultrafine grains in equal-channel angular pressing. Acta Mater 46(5):1589-1599. https://doi.org/10.1016/S1359-6454(97)00355-8

40. Sakai T, Belyakov A, Kaibyshev R, Miura H, Jonas JJ (2014) Dynamic and post-dynamic recrystallization under hot, cold and severe plastic deformation conditions. Prog Mater Sci 60:130-207. https://doi.org/10.1016/j.pmatsci.2013.09.002

41. Sitdikov O, Sakai T, Miura H, Hama C (2000) Temperature effect on fine-grained structure formation in high-strength Al alloy 7475 during hot severe deformation. Mater Sci Eng A 516(12):180-188. https://doi.org/10.1016/j.msea.2009.03.037

42. Sitdikov O, Garipova R, Avtokratova E, Mukhametdinova O, Markushev M (2018) Effect of temperature of isothermal multidirectional forging on microstructure development in the Al-Mg alloy with nano-size aluminides of Sc and Zr. J Alloys Compd 746:520-531. https://doi.org/10.1016/j.jallcom.2018.02.277

43. Zhao I, Deng Y, Zhang J, Ma Z, Zhang Y (2019) Effect of temperature and strain rate on the grain structure during the 
multi-directional forging of the $\mathrm{Al}-\mathrm{Zn}-\mathrm{Mg}-\mathrm{Cu}$ alloy. Mater Sci Eng A 756(2):119-128. https://doi.org/10.1016/j.msea.2019.04. 033

44. Wallace PW, Schey JA (1971) Speed effects in hot closed die forging

45. Avitzure B (1992) Friction during metal forming. ASM International, Materials Park

46. Sethy R, Galdos L, Mendiguren J, Sáenz de Argandoña E (2016) Identification of friction coefficient in forging processes by means T-shape tests in high temperature. KEM 716:165-175. https://doi.org/10.4028/www.scientific.net/KEM.716.165

47. Zeng Y, Chao Y, Luo Z, Cai Y, Song R (2018) Effect of multidirectional forging and heat treatment on mechanical properties of in situ ZrB2p/6061Al composites. High Temp Mater Process 37(7):603-612. https://doi.org/10.1515/htmp-2016-0200

48. Hussain I, Rao PN, Singh D, Jayaganthan R, Singh S (2014) Comparative study of microstructure and mechanical properties of Al 6063 alloy processed by multi axial forging at 77K and cryorolling. Procedia Eng 75:129-133. https://doi.org/10.1016/j. proeng.2013.11.028

49. Mikhaylovskaya AV, Kotov AD, Kishchik MS, Prosviryakov AS, Portnoy VK (2019) The effect of isothermal multi-directional forging on the grain structure, superplasticity, and mechanical properties of the conventional Al-Mg-based alloy. Metals 9(1):33. https://doi.org/10.3390/met9010033

50. Shakhova I, Belyakov A, Kaibyshev R (2014) Effect of multidirectional forging and equal channel angular pressing on ultrafine grain formation in a Cu-Cr-Zr alloy. Mater Sci Eng A 63:12097. https://doi.org/10.1088/1757-899X/63/1/012097

51. Zhang D, Osman M, Li L, Zheng Y, Tong Y (2016) Simulation and experimental investigation for the homogeneity of Ti49.2Ni50.8 alloy processed by equal channel angular pressing. Metals 6(3):45. https://doi.org/10.3390/met6030045

Publisher's Note Springer Nature remains neutral with regard to jurisdictional claims in published maps and institutional affiliations. 